\title{
Rethinking ESP in Algerian Universities: Towards an Adaptable Materials-Design Framework
}

\author{
Dr. Nacereddine Benabdallah \\ University of Mohamed-Cherif Messaadia \\ Souk-Ahras, Algeria
}

\begin{abstract}
One of the most fundamental concerns of post-secondary education is to improve teaching and assure quality through the promotion of research. The aim of the present reflective piece is not to support or challenge a theory but find out new and better ways of doing things. It is an attempt to provide a simple and adaptable framework in order to help ESP teachers at Algerian universities design their own materials in diverse areas and disciplines. This framework takes into consideration not only the learners' real needs but their linguistic cultural and communicative competencies and performances. It has to draw upon authentic materials, real-world tasks, and methodology. It incorporates ESP learners' own experience, confidence and autonomy.
\end{abstract}

Keywords: ESP - framework - authentic materials -needs analysis - learners' experience

\section{Taking Stock of the Situation}

It is undeniable that nowadays English is the first international language of science, aviation, technology, computers, Internet, business, diplomacy, media industry, tourism and even literature par excellence. So a student's chances of getting a good job in a multinational company within their home country or of finding work abroad will be increased when knowing English well. Moreover, learning English enhances scientists and researchers, who are inclined to develop in their field of study, to have access to a myriad of documents and references written in English.

Realizing that fact, Algerian tertiary institutions have been giving importance to the learning of English so that teachers, graduate and postgraduate students can contribute to the development of scientific research and information exchange through publications, articles, conferences and the like. Graduate and postgraduate students are required not only to read and understand documents written in English in relation to their respective fields of study but write texts in English as well. However, due to the fact that I have been a teacher of English for Specific Purposes (ESP) for a long time, things are not always done in the right way because: firstly, there are no clear and well-defined teaching materials, techniques, and courses. Secondly, most of ESP teachers in Algerian universities are inexperienced part-time lecturers. Henceforth, the present study is an attempt to rethink the way ESP has to be taught in Algerian universities. It proposes a simple adaptable materials-design framework that takes into account learners' real needs, interests and attitudes as well as their linguistic and communicative skills in English that are necessary for their own fields of study.

\section{The Scope of ESP}

Generally speaking, ESP refers to the teaching of English for utilitarian purposes. Such purposes are defined in accordance with academic, vocational and occupational requirements. Indeed, ESP is an approach destined to answer the question: 'Why and for which specific purpose does a given learner need to learn English as a foreign language?' According to Dudley-Evans (1997), ESP is concerned with making use of the various methodologies, procedures, techniques, strategies, and activities of a given discipline that meet, most importantly, the needs of adult learners either at a tertiary level institution or in a professional work situation.

ESP differs considerably from EFL in terms of purposes as well the nature of learners and their needs. ESP learners are more familiar with English and more inclined to learn it to develop and communicate professional skills or deal with given job-related functions. On this basis, appropriate ESP syllabuses are designed meeting the purposes and students' needs. In other words, English has to be integrated in the student's main subject matter area and can never, in any case, be separated from the learner's real world.

It is worthy of note that both major trends of ESP, occupational (EOP) and educational or academic (EAP) are closely interrelated because the current global trend is towards learner-centered education. (Strevens, 1977) The economic and instructional developments go hand in hand and whenever the economic world and educational philosophies, approaches, theories, and methods change, teaching and learning English also changes and evolves. 


\section{Teaching ESP in University of Souk-Ahras}

In 2016, a survey was conducted at the University of Souk-Ahras in order to inquire about the teaching situation of ESP. The results obtained from a questionnaire administered to 13 full-time and 07 part-time teachers of English working in six faculties and two institutes show very alarming anomalies and inadequacies:

a. Teachers appointed to teach ESP at Faculty of Human and Social Sciences, Faculty of Law and Politics, Faculty of Biology, Faculty of Technology, Faculty of Economic Sciences and Management, the Institute of Agronomic and veterinary Sciences, and the Institute of Sports, are all part-time inexperienced teachers. They got either a master's or BA degree in English. However, those who were solicited to provide an intensive instruction in English for postgraduate students (magister and doctorate) are all senior lecturers.

b. The absence of official syllabi destined for both graduate and post-graduate students in accordance with their respective field of study. There is no urged coordination between teachers to decide upon what to teach, how to teach, and for which purpose. Each one is left to herself. The practice is limited to choosing a given text in relation to the field of study with a number of activities and voilà everybody is happy.

c. The negative perceptions and attitudes of most students as they believe that ESP is of secondary importance and minor interest. They are reluctant to learn English as there is no clear-cut and well-defined purpose. For them, ESP is another unwanted millstone around their neck. Consequently, they are more inclined to cut lectures, misbehave, and reject learning in all.

d. Very often such students' 'learned helplessness' (Weiner, 1994) and intangible achievement is exacerbated by the unfounded perceptions of all faculty concerned who give much importance to the core subject matter area and neglect the teaching of foreign languages which, undeniably, have real impact on students' learning and future.

Henceforth, the above survey urged us to reflect upon the results, rethink and decide upon a practical and adaptable framework in order to change and improve the way we teach ESP taking into account the real needs of the students concerned as well as the procedures of a well-defined syllabus elaboration. Such framework should be the result of a process made up of five inextricably intertwined stages.

\section{An Adaptable ESP Framework}

\subsection{Foreign Language Pedagogy Renewal}

Stern (1992) states that foreign language teaching renews and improves itself under three basic ways as shown in Figure 1.

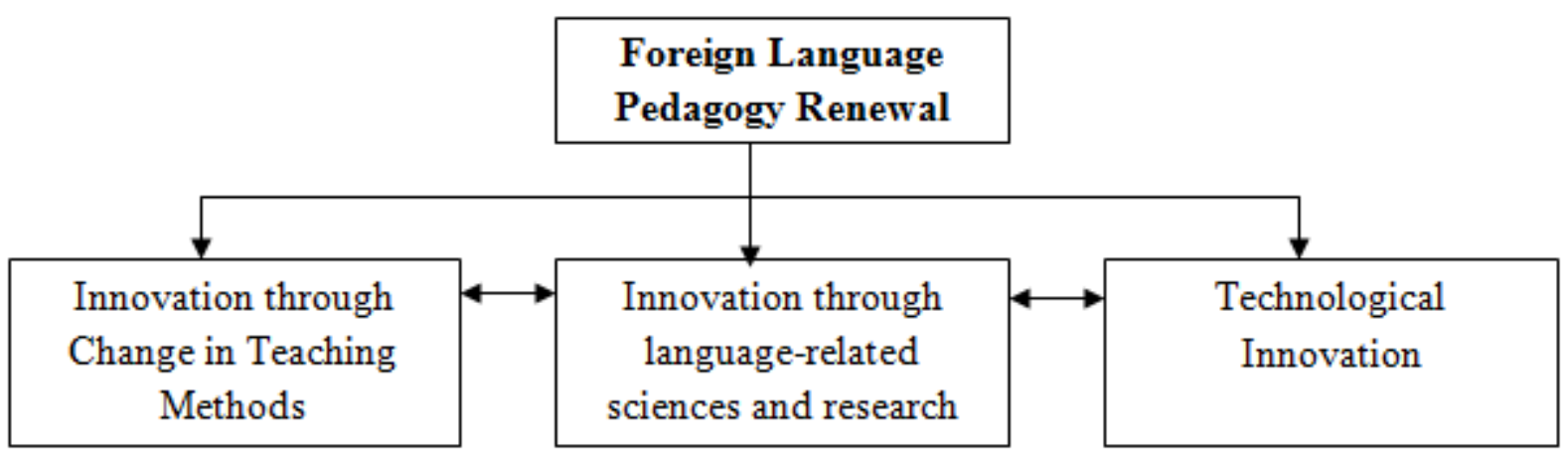

Figure1: Foreign Language Pedagogy Renewal (Adapted from Stern 1992)

According to Stern (1992), changes in teaching methods reflect to a large degree, social, economic, political and educational circumstances and are also significantly influenced by changes in language theories, linguistics, and psychological perspectives on language learning and teaching. As it is known, although new methods signify a certain break from the old, they, very often, maintain a link with the past by incorporating positive and workable aspects of previous paradigms.

The second innovation in Stern's model is inherently multidisciplinary. It derives from deep and elaborate research in the fields of applied linguistics, psychology, psycholinguistics, and sociology. The integration of these disciplines requires the creation of a wide range of initiatives in research, development and pedagogical innovations. Any change and evolution in a field will profoundly influence language pedagogy.

The third core dimension of foreign language teaching and learning refers to the use of various instructing materials and tools by practitioners in their classrooms. It has already been observed that changes in theories of language affect the uses of technology and new technology affects theories of language learning and teaching. (Harmer, 2001) There is a reciprocal interaction between them. 
The elaboration of an adaptable ESP framework has to take into consideration the interrelatedness between changes in teaching methods, procedures, and strategies, changes in language-related sciences, and changes in technology. For example, when ESP covers a given subject matter such as tourism, or business management, it must rely on a given linguistic, psychological, and socio-cultural underlying theory; it must use appropriate teaching method and techniques as well as a facilitating technological tool in order to meet the learners' needs and purposes. Hutchinson and Walters (1987), by the same token, made it clear that "ESP is an approach to language teaching in which all decisions as to content and method are based on the learner's reason for learning." (p. 19)

\subsection{ESP Strategic Planning}

As it has been previously mentioned, the development of an adaptable and integrated ESP framework presupposes the existence of a strategic planning including not only what to be done but how to do it as well. Such plan requires university staff, administrators and students to change their ideas about how teachers teach and how learners learn. They need to show full commitment, involvement and work collaboratively. This process goes through five major stages as it is mentioned in Figure 2.

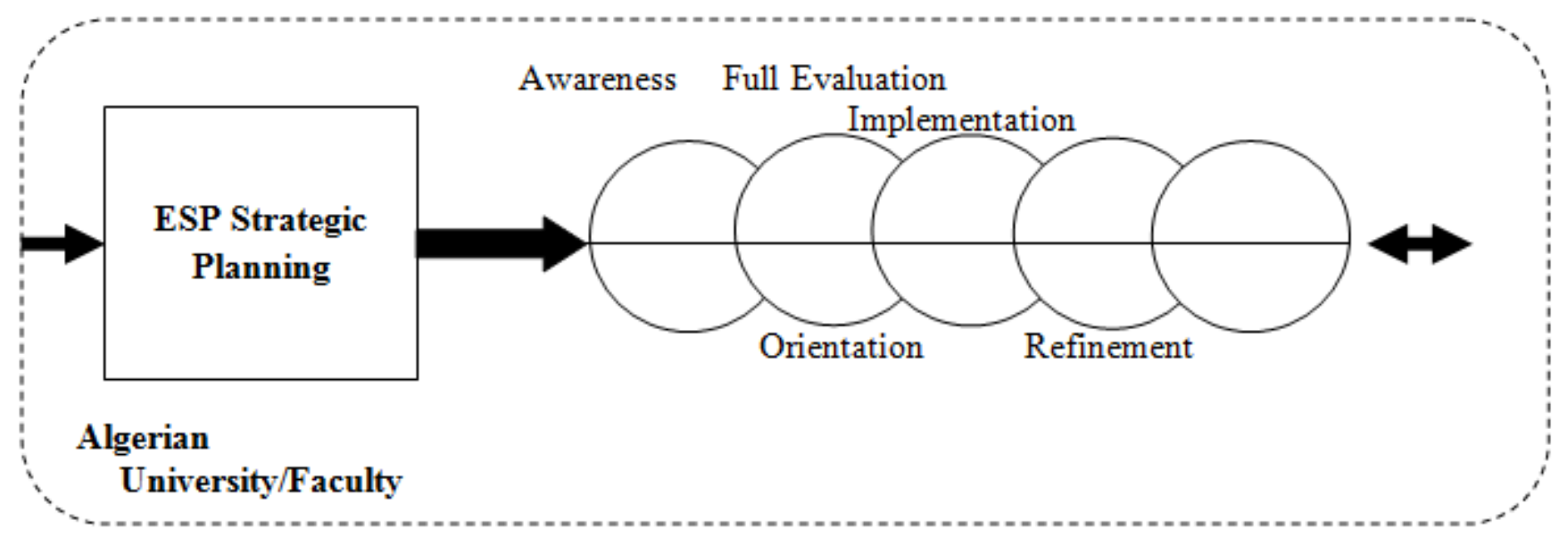

Figure 2: ESP Strategic Planning

Awareness is the first stage. Both ESP teachers and faculty staff concerned have to identify the desired and possible goals of learning English. They need to be aware about what and how to teach their students on the basis of their needs and well-defined purposes. The faculty staff concerned must change their perceptions and attitudes about English and urge ESP teachers to do their best by adopting the most adequate content, teaching method(s), techniques and strategies.

The second stage is orientation. It refers to the fact of taking action firmly. ESP teachers need to work, more particularly if they are part-time teachers, collaboratively with full-time teachers of English and teachers from the faculty concerned. They decide and reflect upon choosing who teaches, what to teach, which strategies and tools to be used on the basis of the learners' needs.

The progress to the stage of full implementation requires time. Ongoing communication between teachers and administration is strengthened. The ESP has a clear view on the students' abilities or weaknesses and real needs. The unfounded and harmful perceptions from the part of the faculty concerned are alleviated through tangible actions regarding, for instance, the group size, timing, and the time devoted to English courses, in order to enhance the status of English teaching and learning. Refinement is the next stage. The decision-making team must be always open to new and more effective ways of teaching ESP in all. At the final stage of evaluation, teachers and faculty authority concerned assess what has been done including the design of the curriculum, the way it has been implemented and the effectiveness of the adaptable ESP framework in achieving desired goals. The evaluation will help them detect and understand the learners' needs, establish new purposes and a corresponding action plan.

\subsection{ESP Materials Design}

The results obtained from our survey indicate clearly that there is neither a syllabus nor an ESP course book made at the disposal of teachers. Instead, they feel free to teach whatever they judge relevant and focus is on language structure, vocabulary and mechanical activities. Communication methodology is totally neglected. Hence, the course becomes boring. Students are frustrated and show provocative and disruptive behaviour. 
The teacher feels stressed, no more motivated and self-confident and very often quits the job. So, there is reason for thinking and designing an adequate ESP materials protocol that takes into account:

a. A thorough analysis of students' needs arranged according to a set of priorities. Necessary information is gathered about the learner, the purposes for which English is needed, the required level of proficiency, the situation of communication and with whom this language will be used. (Nunan, 1988) Moreover, ESP experts contend that it is not quite practical to teach everything about the target language in order not to waste time and effort. Instead, teachers have to provide learners with what they really need. West (1994) made a distinction between target situation needs (what a learner needs to know in order to be effective in a target situation), deficiency analysis (the gap between what the learner actually knows and what he is required to know at the end of the program), and strategy analysis (the appropriate learning methodology and styles to be taken into account).

b. The use of an underlying methodology and activities of the field of study it serves. (Dudley-Evans and St John, 2005). The focus is on the linguistic components like grammar, syntax, vocabulary, and both receptive and productive skills. As for the activities and tasks, they have be authentic i.e. they are genuinely carried out by learners in order to reflect both their educational and professional environments. Hence, ESP teachers and syllabus developers tend to design relevant materials around such high frequency and real-world tasks taking into account students' own experiences and socio-cultural issues.ESP materials destined to management, banking or medicine could derive from the official syllabi of the core modules of the discipline concerned. The duties of a doctor referred to as the code of conduct like for example, listening to patients or explaining diagnosis, breaking bad news can be dealt with through authentic tasks and topic-based ESP courses. Sometimes, students find it difficult to converse in the discourse of the community they belong to. So the role of the ESP teacher is to help them become members of the community concerned with a shared language. In other words, a possible alternative is to design a course that students follow in their first language.

c. The use of authentic spoken and written texts which help students not only grasp the various components of the language that depend on a well-identified context but develop the basic communicative competencies as well. These texts deal with topics that can foster learners' motivation and positive attitudes towards ESP courses. It is more important to opt for authentic texts written by qualified practitioners to experts rather than those written by interested laypersons like journalists for general public. A kind of coordination between the ESP teacher and a content specialist is very desirable.

d. The use of vocabulary activities. There is a serious misconception, according to many experts, that teaching and learning ESP is limited to teaching terminology. In fact, and more particularly nowadays, ESP students do not need at all a foreign language teacher to teach them specialist vocabulary. A good bilingual dictionary can, to a great extent, help them out. According to Ilse Born-Lechleitner(1992), between 9\% and 25\% of an ESP text is made up technical vocabulary that relates to a special field of interest. The job of an ESP teacher is to help learners understand the general non-technical vocabulary and the way it is combined with technical and sub-technical vocabulary in a well-structured text. The ESP teacher may also present activities that deal with familiar and informal language such as idiomatic expressions and euphemisms in order to avoid misunderstandings. Therefore, most of the time, it is not the technical words that cause problems for students but the way they are expressed in sentences. As for the question whether ESP teachers must include grammar activities or not, the debate still prevails. However, many experts and ESP materials writers highlight the importance of accuracy and persist on concentrating on the key grammatical structures that are highly frequent in a given teaching or socio-cultural context.

e. The way to improve ESP students' performance. Ellis and Johnson (1994) state that this performance will be enhanced through accurate use of language, clarity of speech, communicative or coping strategies, and non-verbal communicative features,. A materials-design framework, therefore, must give students the opportunity to effectively develop and apply what they have learnt through performing tasks. Non-verbal communication. Another area that can develop ESP learners' performance is culture awareness. Teachers and writers have to focus on both national and international cultural issues such as lifestyle, religion, beliefs and values, food...etc. Moreover, the use of video as a medium will provide ESP students with authentic real-life interactions. They will be exposed to both the visual and auditory language features. A printed text does not give more information than a video sequence. This latter provides learners with information about the environmental clues, the situational context, and the linguistic and sociocultural background of the interlocutors.

\section{Conclusion}

In all, as it is stated by Tomlinson (1998), Crawford (2002), Vaughan (2011), and Wright (2013), the conception of an effective ESP materials-design process draws upon a set of guidelines. First, an ESP materials writer must prepare a full outline and description of the audience concerned in terms of the field of study, level of linguistic needs, the course itself, and the evaluation protocol. Second, the practitioner seeks to obtain a picture of the students' needs in order to incorporate adequate tasks and methodology that will help learners perform in English in a highly effective way. 
Third, the ESP writer starts designing the lesson by choosing authentic written or spoken texts, and relevant activities bearing in mind vocabulary items, grammatical structures, and cultural features. For more credibility, the writer should turn to an expert for advice. This latter, who is not necessarily an English language expert, can check the technical content, procedures and terminology. Last but not least, an ESP materials-design framework is a cyclical and collaborative process requiring, to a great extent, commitment, determination, and of course sound and reliable goals.

\section{References}

Born-Lechleitner, I. (1992).Words, words, words ... dealing with vocabulary in ESP. Vienna English Working Papers (VIEWS), 2, 1, University of Vienna.

Crawford, J. (2002).The role of materials in the language classroom: finding the balance in methodology in language teaching.CUP.

Dudley-Evans, T. (1997). Genre: how far can we, should we go? World Englishes.16, 3: 351- -368

Dudley-Evans, T., St John, M. (2005).Developments in English for specific purposes.CUP.

Ellis, M., Johnson, C. (1994).Teaching business English, Oxford University Press

Harmer, J. (2001).The practice of English language teaching. London: Longman.

Hutchinson, T., Walters, A. (1987). English for specific purposes: its history and contribution.

In Celce-Murcia, M. (ed). Teaching English as a second or foreign language. Boston, MA: Heinle \& Heinle,. Nunan, D. (1988). Syllabus design. OUP.

Stern, H. (1992). Issues and options in language teaching. OUP

Strevens, P. (1977). Special-purpose language learning: a perspective. Language Teaching 163.

Tomlinson, B. (1998).Materials development in language teaching, (ed.) CUP.

Vaughan, R. (2011). No Niche is too specialist for skilled English language teachers. The Guardian Weekly

Weiner, B. (1992). Human motivation: metaphors, theories, and research. Newbury Park,

CA: $\quad$ SAGE Publications.

West, R. (1994). Needs analysis in language teaching. In Language Teaching. 27, 1-19.

Wright, R. (2013). How to write ESP materials.ELT teacher 2 Writer. 